\title{
Impact of Overcrowding Sous Vide Water Baths on the Thermal Process of Pork Loins
}

\author{
Jessica $\mathrm{Wu}^{1}$, Helen Heacock ${ }^{2}$, Lorraine McIntyre ${ }^{3}$, Sion Shyng ${ }^{4}$ \\ 1 Lead Author, B. Tech Student, School of Health Sciences, British Columbia Institute of Technology, 3700 Willingdon Ave, \\ Burnaby V5G 3H2 \\ 2 Supervisor, School of Health Sciences, British Columbia Institute of Technology, 3700 Willingdon Ave, Burnaby V5G $3 \mathrm{H} 2$ \\ 3 Contributor, BC Centre for Disease Control, 655 West 12th Ave, Vancouver, BC V5Z 4R4 \\ 4 Contributor, BC Centre for Disease Control, 655 West 12th Ave, Vancouver, BC V5Z 4R4
}

\begin{abstract}
Background: In the culinary industry, sous vide is a popular cooking method in which lower temperatures are used to cook food to retain more desirable organoleptic characteristics. However, this technique may compromise food safety as the temperature may not be sufficient enough to eliminate pathogens that may be present. The BCCDC's Guidelines for Restaurant Sous Vide Cooking Safety in British Columbia advises when too many food items are placed in the sous vide water bath, inadequate water circulation may occur with the result that process lethality, measured by calculation of $\log _{10}$ reductions, may not be achieved. The purpose of this study was to determine how overcrowding a sous vide water bath would impact the thermal process of pork loins.
\end{abstract}

Methods: Each pork loin sample had a SmartButton inserted and was vacuum sealed in a plastic bag. The water bath was preheated to $60^{\circ} \mathrm{C}$ by an immersion circulator. Under normal conditions, six pork loin samples were held in the water bath for 1 hour and the process was repeated four more times. Under overcrowded conditions, two runs were conducted for 1.5 to 2 hours, each consisting of 15 samples stacked in three layers. SmartButton temperature values were used to calculate whether a $6.5 \log _{10}$ reduction for Salmonella spp. was achieved, using the American Meat Institute's formula.

Results: Using a 31-minute cook time, pork loins in normal conditions reached an average log reduction of 8.85 (range: 0.51 to 21.07 ), which was significantly higher than the $6.5 \log _{10}$ reduction objective $(\mathrm{p}=0.006)$. Conversely, pork loins in overcrowded conditions reached an average log reduction of 1.76 (range: 0.05 to 7.93 ), which was significantly lower than the $6.5 \log _{10}$ reduction objective $(\mathrm{p}=0.000)$. Furthermore, cooking lethality between the two conditions, pork loins in crowded and overcrowded conditions, were found to be significantly different from each other $(\mathrm{p}$ $=0.000$ ). No differences were found in the mean $\log _{10}$ reductions between the pork loins placed in each of the three layers in an overcrowded water bath at 31 minutes $(\mathrm{p}=0.094)$.

Conclusion: Overcrowding sous vide water baths does impact on the thermal process of pork loins. Food products cooked under overcrowded conditions require a longer cook time, (approximately 30 minutes longer) to achieve at least $6.5 \log _{10}$ reductions. Therefore, it is advised that food handlers using sous vide techniques should avoid overcrowding sous vide water baths. Further research using more samples is recommended to determine potential cold spot patterns in overcrowded water baths due to inadequate water circulation.

Keywords: Sous vide, overcrowding, water bath, pork loin, temperature, public health INTRODUCTION 
Sous vide is a popular cooking technique used by many chefs and home cooks to make high-quality food. Compared to traditional cooking methods, sous vide uses lower temperatures, which can prevent overcooking but can also pose a risk to public health as pathogens present in the food may not be fully eliminated. BCCDC's Guidelines for Restaurant Sous Vide Cooking Safety in British Columbia advise that if too many food items are placed in sous vide water baths, water circulation can be affected and safe internal temperatures may not be achieved. This is a concern since restaurant chefs and home cooks may not be fully aware of the problem and may assume that a certain food is cooked thoroughly even if it is actually undercooked. However, there is no published research to support or refute this part of the guidelines. In order to fill in this knowledge gap, pork loins were used to determine the impact of overcrowding sous vide water baths and how the thermal process of food is affected. There is potential for knowledge translation as this research can inform guidelines and expand the knowledge of chefs, home cooks and Environmental Health Officers (EHOs) on sous vide.

\section{LITERATURE REVIEW}

\section{Sous Vide}

As described by the BC Centre for Disease Control (BCCDC) Environmental Health Services and Sous Vide Working Group, sous vide cooking is a process where foods are vacuum-packaged and immersed in a temperature controlled water bath or steam oven (1). Circulating water baths heat uniformly, whereas steam ovens do not (2). This process can be applied to food such as meat, eggs, seafood and vegetables. Sous vide style cooking can be found in restaurants and at home as immersion circulators used to heat food in water baths are available to the public.

\section{Cooking:}

The technique of sous vide is also described as a low-temperature long-time (LTLT) cooking method, as foods are cooked at lower temperatures for an extended period of time $(1,3)$. According to the BCCDC Environmental Health Services and Sous Vide Working Group, the cooking step in the sous vide cooking method is also described as sous vide pasteurization in which the internal food core temperature is held long enough to achieve a $6.5-\log _{10}$ bacterial reduction (or a $7-\log _{10}$ reduction for poultry) (1). A log reduction means eliminating the number of pathogens by a factor of ten (1). Achieving the recommended $\log _{10}$ reductions is critical to ensure that the bacterial loads are sufficiently eliminated. Come-up time (CUT) is time it takes to reach the target internal core temperature and is dependent on the shape and thickness of the item (1). Full sous vide pasteurization is achieved by sum of the CUT and the additional time the food is held at the target temperature to reach the required log reduction. As stated in the Canadian Food Inspection Agency's (CFIA) Meat Hygiene Manual Procedures, operators manufacturing cooked ready-to-eat meats must indicate the minimum internal temperature reached during the cooking process and the hold time at that temperature to achieve at least $7-\log _{10}$ reduction in poultry or a $6.5-\log _{10}$ reduction for other meat products (4).

Finishing steps may be applied to sous vide foods prior to serving. These steps include applying grill marks to meats, adding ingredients, and reheating before plating (5). Searing can be done in addition to the sous vide cooking step as a finishing step before serving to provide Maillard browning and enhanced flavour (2). Previous British Columbia Institute of Technology (BCIT) student research projects by $\mathrm{Li}$, Do and Plain focused on the efficacy of the searing step on 
achieving sous vide pasteurization $(3,6,7)$. Do's study on chicken breast found that searing chicken helped achieve sous vide pasteurization of $7-\log _{10}$ reduction (6). In contrast, Li's results showed found that the additional searing step did not help achieve sufficient sous vide pasteurization of salmon for a $6.5-\log _{10}$ reduction (3). Plain concluded in her study on duck breasts that the sous vide cooking method should be used to achieve the majority of the required $7-\log _{10}$ reduction and searing can only be used for small $\log _{10}$ reductions (7). Searing as a process control step is not ideal, as the temperatures occur at a very high temperature for a very short time, and the results are variable.

\section{Water Circulation and Overcrowding:}

The water bath used for sous vide is heated and circulated with an immersion circulator. An immersion circulator provides heat with its heating coil and facilitates water circulation with its pump (1). Adequate water circulation is needed for an even heat distribution throughout the sous vide water bath. To achieve adequate water circulation, the BCCDC Environmental Health Services and Sous Vide Working Group recommends to not add too many vacuum packaged food items into the water bath, nor stack them on top of each other, nor have them touch each other (1). Otherwise, there may be cold spots in certain areas in the water bath and heat penetration may be slower $(1,5)$. This will affect the CUT since the food in the water bath will take longer to reach the required internal temperature, furthermore prolonging the time required to achieve full sous vide pasteurization. In Vikraman's study, he observed the sous vide cooking process carried out in Metro Vancouver restaurants and found that some chefs were unaware of sufficient holding times and temperatures required for food products (8). This can be problematic if chefs were to remove the food out of the water bath before it is held long enough at a high enough temperature. Therefore, it is important for chefs to be aware that CUTs could be longer depending on how many food items are placed in water and that they may need to keep the food in the water bath for a longer period of time.

\section{Cooling and Storage:}

Sous vide prepared food should be immediately cooled to safe temperatures of less than $3.3^{\circ} \mathrm{C}$ and should not be stored for longer than 7 days (1). Sous vide cooking methods, similar to other conventional cooking methods (e.g. oven baking) reduce bacterial numbers, but do not reduce pathogenic spores to a safe level, any pathogenic spores: this requires pressure and temperature (e.g. canning). Because sous vide foods are vacuum packaged, botulism is considered a hazard as the food is stored in an anaerobic environment. To ensure safety and limit the risk from pathogenic spores germinating and producing harmful toxins, sous vide foods must be rapidly chilled and refrigerated (2). The time it takes to cool depends on the thickness and shape of the food (9). Chefs of the Sous Vide Working Group suggested to cool sous vide food immediately to $3^{\circ} \mathrm{C}$ or below within two hours by using an ice-water bath (1). Although $3^{\circ} \mathrm{C}$ is out of the temperature danger zone of $4^{\circ} \mathrm{C}$ to $60^{\circ} \mathrm{C}$, it is important to be aware that this temperature is not low enough to prevent of the growth of some pathogens such as Listeria monocytogenes which are capable of surviving at temperatures as low as $-0.4^{\circ} \mathrm{C}(10)$.

\section{Reheating:}

When sous vide cooked food is reheated for service, it is reheated in a water bath at or below the temperature in which it was cooked (2). The water bath temperature is typically set at 53 to $55^{\circ} \mathrm{C}$ because the optimal serving temperature for meat is between 50 to $55^{\circ} \mathrm{C}$ (2). The BCCDC Environmental Health 
Services and Sous Vide Working Group stated that foods reheated below $55^{\circ} \mathrm{C}$ cannot be held longer than two hours, otherwise they must be discarded (1). Foods reheated to temperatures over $55^{\circ} \mathrm{C}$ can be held without a limit for time, but must not be reheated again, and thrown away at the end of that day (1). According to the Food Retail and Services Code, foods are at risk as they pass the danger zone several times through hot holding, serving, cooling and reheating processes (11). Reheating to at least $74^{\circ} \mathrm{C}$ is the advice applied to foods cooked by other methods, as it is important to destroy any pathogens that may be introduced to the food by contamination.

\section{Advantages:}

This cooking technique has been trending in the culinary industry as it can achieve optimal organoleptic characteristics. Cooking food in the sous vide water bath can provide precise control over the cooking temperature since the temperature of the food will not exceed the water bath temperature, preventing the food from being overcooked (1). As a result, sous vide style foods retain their moisture, tenderness, and flavour (1,2). Since myogoblin, oxymygoblin and metmyogoblin proteins are not denatured by the lower cooking temperature, meats can retain its red colour as well $(1,2)$. Compared to conventional cooking methods such as steaming and boiling, sous vide also retains nutrients such as omega-3 fatty acids in fish and vitamins and minerals in vegetables $(2,12)$. The ability to retain these desirable characteristics makes sous vide a popular cooking technique used by many chefs.

\section{Risks and Safety Concerns}

Despite the advantage of retaining ideal organoleptic qualities in food by using sous vide cooking methods, there are safety concerns that cannot be overlooked. Chemical hazards can occur in sous vide foods if the plastic packaging is not food grade. Inadequate time and temperature control of sous vide foods can pose microbiological hazards that lead to major health concerns. Proper preparation, cooking, cooling, storage and reheating steps are necessary to prevent pathogen survival and growth.

\section{Chemical Hazards:}

Plastic packaging is used to vacuum seal food in preparation for sous vide cooking. Migration of plastic constituents from the packaging to food is a health concern (1). The vacuum packaging should be food grade and should have qualities such as resistant to high temperatures, low permeability to gases such as oxygen and vapour, sufficient mechanical strength, and limited migration of plastic constituents (12).

\section{Microbiological Hazards:}

Like many other foods, sous vide foods can be microbiologically contaminated through improper food handling practices. Pathogens of most concern include those that form spores and survive in anaerobic conditions or facultative anaerobic conditions provided by vacuum-packaging (1). Spore formers include Clostridium botulinum, Bacillus cereus and Clostridium perfringens. These spore formers can produce toxins and their spores are highly heat-resistant. In addition to its spore forming characteristic, C. botulinum can survive in anaerobic and psychotropic conditions as they can grow and produce toxin in temperatures less than $10^{\circ} \mathrm{C}(1,12)$. Non-spore forming facultative anaerobic bacteria that are also of concern include Salmonella spp., pathogenic strains of Escherichia coli, Staphylococcus aureus, Yersinia enterocolitica, Listeria spp. and Vibrio spp. (1). In addition, any air pockets formed during vacuum packaging may also be problematic. Not only do they act as insulators by reducing the heat transfer rate in 
food through the package, but they also provide ideal conditions for the growth of aerobic bacteria $(1,8)$. Therefore, cooking sous vide food to safe internal temperatures is essential to eliminate these pathogens and to prevent food poisoning.

\section{Foodborne Illness Case linked to Sous Vide Food:}

A recent study by McIntyre determined that three cases of Salmonella Enteritidis illnesses in British Columbia were potentially linked to sous vide foods in 2014 (5). Once the Vancouver Coastal Heath Authority was informed, a questionnaire was given to the cases. The results linked one illness to a restaurant that served sous vide duck breasts and the other two illnesses were identified at another restaurant that served sous vide eggs (5). This warranted an investigation at the restaurants identified. EHOs observed food handling practices, food safety plans and sous vide procedures. The restaurant that served sous vide duck breasts did not have a working thermometer at the time of inspection and did not monitor the immersion circulator or keep any records of internal food temperatures and other critical time and temperatures such as CUT (5). In addition, the staff at this restaurant did not know how to use sous vide equipment properly (5). The sous vide eggs served in the other restaurant did not reach the temperature set by the immersion circulator as they were held in an unperforated bowl that did not allow water circulation around the eggs (5). This restaurant did not have a food safety plan or a sanitation plan in place (5). As a result of this investigation, it is essential that operators have food safety plans that outline sous vide procedures and monitor and record critical time and temperatures.

\section{Pathogens Associated with Pork}

Pathogens of concern for sous vide style food are also associated with pork. These pathogens include Salmonella spp. $L$. monocytogenes, and $S$. aureus $(13,14)$. Other pathogens associated with pork include bacteria such as Campylobacter spp. and parasites such as Trichinella spiralis, Toxoplasma gondii and Taenia solium (13,15-17). Campylobacter spp. are facultative anaerobes and are identified as a top contributor to human gastrointestinal illness (13). T. gondii can cause a disease called toxoplasmosis, which is a public health concern to the immunocompromised, especially AIDS patients, who are more susceptible (13). Another risk group of concern for toxoplasmosis is pregnant women as the disease can cause miscarriage, stillbirths and numerous health problems in living fetuses (13). T. spiralis cysts can migrate and invade muscle tissue, leading to inefficiency of muscle contraction, muscle pain, myalgia and joint pain $(13,15) . T$. solium infection a serious disease that cause seizures and muscle or eye damage (16). The main preventative measure to prevent the growth and survival of the aforementioned pathogens is adequate cooking. To the best of the author's knowledge, there are no known cases of illness associated with sous vide pork.

\section{Legislation and Guidelines}

There is currently no legislation that is specific to sous vide cooking. However, according to the Public Health Act, SBC 2008, c 28, s 15, "a person must not willingly cause a health hazard, or act in a manner that the person knows, or ought to know, will cause a health hazard" (18). The Food Safety Act, SBC 2002, c 28, s 2, specifies that "an operator is responsible for ensuring that the food in his or her food establishment is safe for human consumption" (19). Hence, chefs are responsible to ensure food safety when they use sous vide methods to cook food. As per the Food Premises Regulation, BC Reg $210 / 99$, s 1 , potentially hazardous food is 
defined as "food in a form or state that is capable of supporting the growth of diseasecausing micro-organisms or the production of toxins" (20). The Food Premises Regulation, BC Reg 210/99, s 2.1 (1) (b) also states that potentially hazardous food is prescribed as a health hazard (20). As mentioned previously, sous vide prepared food is capable of supporting the growth of pathogens and toxin production, thus it has the conditions for it to become a health hazard. Therefore, EHOs should apply their professional discretion in evaluating sous vide practices.

Chefs and EHOs of the BCCDC Environmental Health Services and Sous Vide Working Group developed the Guidelines for Restaurant Sous Vide Cooking Safety in British Columbia. A previous BCIT student research project concluded that EHOs who have reviewed the guidelines have better inspection practices and more knowledge on sous vide cooking than EHOs who have not read the guidelines (21). Although this guideline is based on recommendations and cannot be enforced, it is a valuable resource that provides information to chefs, home cooks and EHOs on safe sous vide practices.

\section{Public Health Significance}

\section{Disclosure to Customers:}

To protect public health, restaurant staff should disclose the potential risks of consuming sous vide foods to individuals in risk groups $(1,5)$. These risk groups include young children, pregnant women, the elderly and immunocompromised people who are more susceptible to foodborne illnesses. Restaurant staff can inform customers by adding menu warnings, posting signs, or disclosing verbally when these foods are ordered. This will allow consumers to make an informed dining choice.

\section{Relevance to Environmental Health Officers:}

EHOs should be well informed about sous vide practices to educate chefs so that they would have sufficient knowledge on safe sous vide practices $(5,21)$. By being aware about the food safety risks regarding sous vide, EHOs will know what to look for during inspections and identify any improper sous vide practices. EHOs should assess food safety plans, critical time and temperature records, observe food handling practices during their inspections and provide education (5).

\section{PURPOSE OF STUDY}

The purpose of this study was to assess the impact of overcrowding sous vide water baths on the thermal process of pork loins. This was determined by examining if there is a difference between the number of log reductions in pork loins cooked in a nonovercrowded water bath versus pork loins cooked in an overcrowded water bath at a specific time.

\section{METHODS}

\section{ACR SmartButton and TrendReader}

ACR SmartButton data loggers were used to measure and record the internal temperature of each pork loin samples during the sous vide process. To control the SmartButtons and access their data, the TrendReader ${ }^{\circledR}$ software was installed on a personal computer according to the manual. The SmartButtons were submerged in an icewater bath with a calibrated VWR Traceable ${ }^{\circledR} \quad$ Ultra $^{\mathrm{TM}}$ waterproof food thermometer. The temperature readings measured by the SmartButtons and calibrated thermometer were compared to each other to ensure that the SmartButtons read temperatures $\pm 1{ }^{\circ} \mathrm{C}$ of the temperature readings measured by the calibrated 
thermometer. For each SmartButton, the data collection start time was programmed to 15 minutes before the start of the experiment and the data collection interval was set to 1 minute.

\section{Immersion Circulator}

The immersion circulator that was used in this experiment is the Anova Precision ${ }^{\mathrm{TM}}$ Cooker. Prior to the start of the experiment, the immersion circulator was clamped onto the short side of a plastic tank filled with 18 $\mathrm{L}$ of tap water and was set to $60^{\circ} \mathrm{C}$ according to the manual. A temperature probe connected to a calibrated Sper Scientific 4 Channel Datalogging thermometer was submerged into the water bath to calibrate the immersion circulator. The datalogging thermometer was also used to ensure that the temperature of the water bath reached $60^{\circ} \mathrm{C}$ before the start of each experiment run.

\section{Pork Loin Preparation}

Pork loins were taken out of a cooler at $4^{\circ} \mathrm{C}$. The pork loins were cut and trimmed into slices and weighed with a calibrated Ohaus compact scale CS 5000. Each slice was 20 to $23 \mathrm{~mm}$ in thickness and 155 to 165 grams in weight. A small incision (approximately 10 $\mathrm{mm}$ ) was made into the thickest part of each pork loin slice and a programmed SmartButton was inserted. Each sample was then labelled and vacuum sealed in foodgrade polyethylene bags using the FoodSaver ${ }^{\circledR} \quad$ FM5400 2-in-1 food preservation system. After vacuum sealing, each bag was visually inspected for presence of air pockets. Any packages found with air pockets were repackaged again. After vacuum sealing, the samples were transferred back into the cooler to ensure that all slices were at the same temperature before the start of experiment.

\section{Experiment Method}

\section{A. Normal Conditions}

After the immersion circulator heated the sous vide water bath to $60^{\circ} \mathrm{C}, 6$ packages of prepared pork loin samples were removed from the cooler and placed into the sous vide water bath for 1 hour (22). This procedure was repeated 4 more times. A total of 5 runs of 6 samples (30 samples) were conducted under normal (non-overcrowded) conditions. Pork loins cooked under normal conditions were used as the control.

\section{B. Overcrowded Conditions}

Once the sous vide water bath was heated to $60^{\circ} \mathrm{C}$, 15 samples were removed from the cooler and were placed into the water bath for 1.5 to 2 hours as the pork loins under this condition may require a longer time to achieve full sous vide pasteurization at $60^{\circ} \mathrm{C}$ (5). This procedure was repeated once more with a second set of 15 samples. A total of 30 samples were used under overcrowded conditions.

\section{Data Collection}

SmartButtons were removed from each sample after the sous vide process. Temperature and time data recorded by each SmartButton were retrieved by the TrendReader ${ }^{\circledR}$ software. To determine the number of $\log$ reductions achieved, each data set was inputted into the AMI Process Lethality Determination Spreadsheet in Microsoft Excel (23). Additional information was also required for the log reduction calculation such as the organism and product of concern and their corresponding reference temperature $\left(\mathrm{T}_{\text {ref }}\right)$, D-value and Z-value. The organism of concern was Salmonella spp. and its reference temperature was $140^{\circ} \mathrm{F}\left(60^{\circ} \mathrm{C}\right)$. Ham was selected as the product of concern as it has a similar meat protein composition as pork loin (22). Hence, a D-value of 1.50 minutes and a $\mathrm{Z}$-value of $10.71^{\circ} \mathrm{F}$ for ham were used (24). For each of the samples cooked under normal conditions, $\log _{10}$ 
reductions that reached to at least $6.5 \log _{10}$ reductions were recorded. The minimum time required for each sample cooked under normal conditions to reach at least $6.5 \log _{10}$ reductions were also recorded. The average minimum time was 30.83 minutes, which rounds up to 31 minutes. For each of the samples cooked under normal and overcrowded conditions, the $\log _{10}$ reductions reached at 31 minutes were calculated and recorded. These values were used in both of the descriptive and inferential statistical analyses.

\section{STATISTICAL ANALYSIS AND RESULTS}

\section{Description of Data}

In this study, numeric continuous data of time (minutes) and temperature $\left({ }^{\circ} \mathrm{F}\right)$ were collected for each sample. As mentioned in the experimental procedure, the data set from each sample was inputted into a Microsoft Excel spreadsheet to calculate the $\log _{10}$ reductions achieved in 31 minutes.

\section{Descriptive Statistics}

Based on the data, the descriptive statistics for the two sample groups under normal and overcrowded conditions were summarized in Table 1 and Table 2 respectively.

Table 1. Descriptive statistics for $\log _{10}$ reductions achieved in 31 minutes in pork loins under normal conditions.

\begin{tabular}{|l|l|}
\hline Mean & $8.75 \log _{10}$ reductions \\
\hline Median & $8.25 \log _{10}$ reductions \\
\hline Mode & $12.88 \log _{10}$ reductions \\
\hline Standard Deviation & $4.65 \log _{10}$ reductions \\
\hline Range & $20.56 \log _{10}$ reductions \\
\hline Minimum & $0.51 \log _{10}$ reductions \\
\hline Maximum & $21.07 \log _{10}$ reductions \\
\hline Count & 30 \\
\hline
\end{tabular}

Table 2. Descriptive statistics for $\log _{10}$ reductions achieved in 31 minutes in pork loins under overcrowded conditions.

\begin{tabular}{|l|l|}
\hline Mean & $1.76 \log _{10}$ reductions \\
\hline Median & $0.58 \log _{10}$ reductions \\
\hline Mode & $0.05 \log _{10}$ reductions \\
\hline Standard Deviation & $2.24 \log _{10}$ reductions \\
\hline Range & $7.89 \log _{10}$ reductions \\
\hline Minimum & $0.04 \log _{10}$ reductions \\
\hline Maximum & $7.93 \log _{10}$ reductions \\
\hline Count & 30 \\
\hline
\end{tabular}

\section{Inferential Statistics}

The statistical packages used for analyzing the data was the NCSS 12 statistical software (25).

Table 3. Results of inferential statistics generated by NCSS 12 data analysis, where $\mu$ is the mean $\log _{10}$ reductions of Salmonella spp.

$\mathbf{H}_{\mathbf{0}}$ : Pork loins cooked under normal conditions at 31 minutes will have $\mu \leq 6.5 \log _{10}$ reductions of Salmonella spp.

$\mathbf{H}_{\mathbf{A}}$ : Pork loins cooked under normal conditions at 31 minutes will have $\mu>6.5 \log _{10}$ reductions of Salmonella spp.

Test Used: One-Sample T-Test

Results: P-value $=0.006$; Power $=0.828$

Conclusion: Reject $\mathrm{H}_{0}$ and conclude that the mean $\log _{10}$ reductions in pork loins cooked under normal conditions is statistically significantly greater than $6.5 \log _{10}$ reductions of Salmonella spp. at 31 minutes.

$\mathbf{H}_{\mathbf{0}}$ : Pork loins cooked under overcrowded conditions at 31 minutes will have $\mu \geq 6.5 \log _{10}$ reductions of Salmonella spp.

$\mathbf{H}_{\mathrm{A}}$ : Pork loins cooked under overcrowded conditions at 31 minutes will have $\mu<6.5 \log _{10}$ reductions of Salmonella spp.

Test Used: Wilcoxon Signed-Rank Test

Results: P-value $=0.000$; Power $=1.000$

Conclusion: Reject $\mathrm{H}_{0}$ and conclude that the mean $\log _{10}$ reductions in pork loins cooked under overcrowded conditions is statistically 
significantly less than $6.5 \log _{10}$ reductions of Salmonella spp. at 31 minutes.

$\mathbf{H}_{\mathbf{0}}$ : There is no difference in the mean $\log _{10}$ reductions of Salmonella spp. in pork loins cooked under normal conditions when compared to pork loins cooked under overcrowded conditions at 31 minutes.

$\mathbf{H}_{\mathbf{A}}$ : There is a difference in the mean $\log _{10}$ reductions of Salmonella spp. in pork loins cooked under normal conditions when compared to pork loins cooked under overcrowded conditions at 31 minutes.

Test Used: Mann-Whitney U Test

Results: P-value $=0.000 ;$ Power $=1.000$

Conclusion: Reject $\mathrm{H}_{0}$ and conclude that there is a statistically significant difference in the mean $\log _{10}$ reductions of Salmonella spp. in pork loins cooked under normal conditions when compared to pork loins cooked under overcrowded conditions at 31 minutes.

$\mathbf{H}_{\mathbf{0}}$ : There is no difference in the mean $\log _{10}$ reductions of Salmonella spp. between the pork loins placed on the bottom, middle and top layers of an overcrowded water bath at 31 minutes.

$\mathbf{H}_{\mathbf{A}}$ : There is a difference in the mean $\log _{10}$ reductions of Salmonella spp. between the pork loins placed on the bottom, middle and top layers of an overcrowded water bath at 31 minutes.

Test Used: Kruskal-Wallis One-Way ANOVA on Ranks Test

Results: P-value $=0.094$; Power $=0.343$

Conclusion: Do not reject $\mathrm{H}_{0}$ and conclude that there is no difference in the mean $\log _{10}$ reductions of Salmonella spp. between the pork loins placed on the bottom, middle and top layers of an overcrowded water bath at 31 minutes.

\section{DISCUSSION}

Based on the conclusions of the statistical analysis on the four inferential statistics tests, overcrowding sous vide water baths does have an impact on the thermal process of pork loins. Since the mean $\log _{10}$ reductions in pork loins under normal and overcrowded conditions were 8.75 and $1.76 \quad \log _{10}$ reductions respectively, it was determined that samples cooked under normal conditions achieved CFIA's and the BCCDC sous vide guideline's minimum standard of $6.5 \log _{10}$ reductions of Salmonella spp. $(1,26)$, whereas samples cooked under overcrowded conditions did not. In addition, samples cooked under normal conditions achieved greater mean $\log _{10}$ reductions than samples cooked under overcrowded conditions at 31 minutes, suggesting that by overcrowding sous vide water baths, the samples require a longer cook time (approximately 30 minutes more) to achieve at least $6.5 \log _{10}$ reductions for full sous vide pasteurization.

The experimental findings agree with the recommendations outlined in the BCCDC's sous vide guidelines and McIntyre, Jorgenson and Ritson's research: water baths should not be overcrowded with too many pouches of food $(1,5)$. The samples in overcrowded conditions required a longer cook time as the water circulation around each sample and the heat exchange were reduced (5). This was because the overcrowded conditions contain a larger mass of pork loins for the temperature of the water bath temperature to penetrate into each of the samples.

Another factor was that the water temperature initially dropped when introducing the refrigerated samples, implying that it would take additional time for the temperature to recover before heating the samples. The findings also reinforces the implications from Vikraman's study, which outlined the importance of awareness amongst food handlers who use sous vide technique, as overcrowding water baths would interfere with the desired time- 
temperature combinations and potentially pose a health hazard (8).

In addition, the Kruskal-Wallis One-Way ANOVA on Ranks test determined that there was no significant difference in the mean $\log _{10}$ reductions between the pork loins placed on the bottom, middle and top layers of an overcrowded water bath at 31 minutes, although there is a potential beta error due to the low power of $0.343(34.3 \%)$. Despite this result, uneven heating shown as the mean $\log _{10}$ reductions reached in pork loins placed on the top, middle and bottom layers in the water bath were $2.791,0.998,1,499 \log _{10}$ reductions respectively. The top layer of pork loins had the highest number of $\log _{10}$ reduction compared to the other two layers because the heated water was able to circulate around the top of the water bath, whereas the middle layer had the lowest number of $\log _{10}$ reductions because this layer was placed between the top and bottom layers, interfering with the water circulation around this layer. Additionally, since the samples were refrigerated, the cold samples on the top and bottom layer also slowed the rate of heat penetration in the samples in the middle layer. BCCDC's sous vide guideline also indicated that inadequate circulation would create cold and warm spots within the water bath. However, this was inconclusive based on this study. There appears to be no pattern indicating a specific cold spot of concern. The absence of a pattern could be due the lack of experimental runs and the differences in size and shape of each sample, hence patterns can possibly be observed with more experimental runs.

\section{LIMITATIONS}

\section{Sample Size}

Due to budget and time restraints, each of the layers had only ten samples for both of the overcrowding experimental runs. During the experiment, plenty of space in the water bath for additional layers was observed. This limitation contributed to a beta error which was determined by the Kruskal-Wallis OneWay ANOVA on Ranks test. Also, even though each sample was prepared in the same way by the same person, the shape, size, and fat to meat ratio of each sample were different as the matrix of individual pork loin differs from one another.

\section{Setting of Experiment}

Since the experimental runs were carried out in a household kitchen, other factors such as humidity and ambient temperature could affect the results of this study. Compared to commercial coolers, the household cooler that was used for the experiment could be less efficient and slower in temperature recovery than commercial coolers. Hence, cooling the temperature of the pork samples to $4^{\circ} \mathrm{C}$ was time consuming. When taking each sample out of the cooler, the temperature of the kitchen increased temperature of the samples before they were placed into the water bath. However, conducting experiments in household settings could reflect actual conditions in household or restaurant kitchens that use household coolers.

\section{Materials}

As more experimental runs were carried out, it was observed that the plastic lid of the water bath tank became deformed. The lid concaved in and created openings on the sides of the tank, allowing heat to escape from the water bath through the gap and dropped the water bath temperature slightly. As this could affect the heating rate of the samples, the lid had to be taped and weighed down to ensure that there were no more gaps. After sealing off the gaps, the water bath temperature recovered to $60^{\circ} \mathrm{C}$ again.

\section{RECOMMENDATIONS}


With respect to the methodology used in this study, to improve the internal and external validity of this study, it is recommended to increase the sample size for overcrowding conditions to minimize potential beta errors. This may also increase the power and confidence in this study. Additional layers of samples could be added to make it more crowded. Also, increasing the sample size and number of experimental runs in overcrowding conditions could possibly show a pattern of where specific cold spots would be in the water bath. To reduce sample preparation time, a commercial cooler that is more efficient at cooling could be used to cool the samples evenly and quickly.

Overcrowding sous vide water bath can pose a risk to public health since heat penetration would not be sufficient enough to kill the presence of pathogens associated with sous vide pork, especially the anaerobic and heat resistant strains that can also produce toxins. Therefore, it is recommended that EHOs should be aware of the importance of not overcrowding and adding too many pouches of sous vide food into water baths. Likewise, chefs must also recognize that overcrowding can slow the sous vide process, and they must be able to demonstrate that they have measured the CUT and pasteurization time for their recipe based on normal cooking conditions. This information should be available to EHOs on request.

\section{KNOWLEDGE TRANSLATION}

Although only pork loins were used in this study, the results are not limited to sous vide pork loins. The heat penetration rate is different in all food products as the matrix of each food product is different. Despite this, the different heat penetration rates of other food, the results of this study can be applicable to other foods in general as well. These results can be presented to those in
BCIT's Environmental Health Program and the BCCDC Environmental Health Services and Sous Vide Working Group. The effects of overcrowding sous vide water baths determined by this study can be incorporated into BCCDC's sous vide guidelines to be viewed by the public. The results from this study can enhance EHOs' and operators' knowledge of proper sous vide practices through attending workshops and reading the sous vide guidelines. EHOs can also implement this knowledge into their inspections of restaurants that adopt sous vide technique and educate restaurant operators on the importance of not overcrowding the water baths.

\section{FUTURE RESEARCH}

Potential areas of research are listed as follows:

- Use different foods such as fish, poultry and other meats in overcrowded conditions to see if similar results are obtained.

- Determine the effects of overcrowding steam ovens, which is an alternative equipment used to sous vide food products instead of immersion circulators.

- Determine the maximum optimal food packages to water bath volume ratio to quantify and define what ratio is considered to be overcrowded objectively.

- Conduct a survey to determine if food handlers who use the sous vide technique would usually overcrowd their sous vide water baths.

\section{CONCLUSION}

Improper sous vide practices can cause inadequate heating of food products and can therefore pose a risk to public health due to survival of any pathogens present. The data 
showed that overcrowding sous vide water baths have an impact on the thermal process of pork. The data also suggests that food products cooked under overcrowded conditions will require a longer cook time, about 30 minutes more) to achieve the standard of at least $6.5 \log _{10}$ reductions for full sous vide pasteurization compared to food products cooked under nonovercrowded conditions. Therefore, findings from this study recommends that food handlers using sous vide techniques should avoid overcrowding sous vide water baths. EHOs should become familiarized with proper sous vide practices and emphasize the importance of not overcrowding sous vide water baths to restaurant operators during restaurant inspections. Based on the data from this study, it is inconclusive that inadequate water circulation would form cold and warm spots within the sous vide water bath. Hence, further research using more samples to detect potential cold spot patterns is recommended.

\section{ACKNOWLEDGEMENTS}

The author would like to acknowledge Lorraine McIntyre and Sion Shyng from BCCDC for the providing valuable resources, equipment and guidance. This study was also suggested by Lorraine McIntyre. In addition, the author would like to thank Helen Heacock her ongoing support during the study and for providing valuable advice. Lastly, author would also like to thank BCIT and Fred Shaw for providing the samples and additional equipment used in this study.

\section{COMPETING INTERESTS}

The authors declare that they have no competing interests.

\section{REFERENCES}

1. BC Centre for Disease Control Environmental Health Services and Sous Vide Working Group. Guidelines for restaurant sous vide cooking safety in British Columbia. 2016; Available from: http://www.bccdc.ca/resourcegallery/Documents/Guidelines and Forms/Guidelines and Manuals/EH/FPS/Food/SVGuidelines FinalforWeb.pdf

2. $\quad \bar{B}$ aldwin DE. Sous vide cooking: A review. Int J Gastron Food Sci [Internet]. 2012;1(1):15-30.

Available from: http://dx.doi.org/10.1016/j.ijgfs.2011. 11.002

3. Li RC. Sous vide salmon pasteurization temperature. BCIT Environmental Health Journal [Internet]. 2015;1-17. Available from: https://circuit.bcit.ca/repository/island ora/object/repository\%3A64?solr_nav $\% 5 \mathrm{Bid} \% 5 \mathrm{D}=\mathrm{e} 25 \mathrm{c} 628390 \mathrm{bebc062f82}$ \&solr_nav $\% 5$ Bpage $\% 5 \mathrm{D}=0 \&$ solr_na $\mathrm{v} \% 5$ Boffset $\% 5 \mathrm{D}=0$

4. Canadian Food Inspection Agency. Cooking - Chapter 4 - Meat Processing Controls and Procedures Food - Canadian Food Inspection Agency [Internet]. 2016 [cited 2018 Mar 18]. Available from: http://www.inspection.gc.ca/food/mea t-and-poultry-products/manual-ofprocedures/chapter-

4/eng/1367622697439/136762278756 8 ? chap $=6 \#$ s $8 \mathrm{c} 6$

5. McIntyre L, Jorgenson V, Ritson M. Sous vide style cooking practices linked to Salmonella enteritidis illnesses. Environmental Health Review [Internet]. 2017;60(2):42-9. Available from: http://pubs.ciphi.ca/doi/10.5864/d201 


\section{7-014}

6. Do N. Sous vide chicken pasteurization temperatures. BCIT student research project for $\mathrm{ENVH}$ 8410. 2013;1-49.

7. Plain S. Examining the safety of duck breast prepared the sous vide method. BCIT Environmental Health Journal [Internet]. 2016;1-11. Available from: https://circuit.bcit.ca/repository/island ora/object/repository\%3A410?solr_na $\mathrm{v} \% 5 \mathrm{Bid} \% 5 \mathrm{D}=\mathrm{e} 25 \mathrm{c} 628390 \mathrm{bebc} 062 \mathrm{f} 8$ 2\&solr_nav $\% 5$ Bpage $\% 5 \mathrm{D}=0 \&$ solr_n av $\% 5$ Boffset $\% 5 \mathrm{D}=2$

8. Vikraman V. Investigation of food safety issues associated with sousvide practices observed in Vancouver restaurants. Faculty of Land and Food Systems. Vancouver, University of British Columbia. Master of Food Science. 2011;1-31.

9. NSW Government Food Authority. Sous vide - Food safety precautions for restaurants [Internet]. 2012 [cited 2017 Oct 18]. Available from: http://www.foodauthority.nsw.gov.au/ _Documents/scienceandtechnical/sou s_vide_food_safey_precautions.pdf

10. Health Canada. Policy on Listeria monocytogenes in ready-to-eat foods (2011) [Internet]. 2015 [cited 2017 Oct 23]. Available from: https://www.canada.ca/en/healthcanada/services/foodnutrition/legislationguidelines/policies/policy-listeriamonocytogenes-ready-eat-foods2011.html

11. Federal/Provincial/Territorial Food Safety Committee. Food Retail and Food Services Code [Internet]. 2016 [cited 2017 Oct 17]. Available from: http://www.hss.gov.yk.ca/pdf/foodser vicescode.pdf

12. Schellekens M. New research issues in sous-vide cooking. Trends Food Sci Technol. 1996;7(8):256-62.

13. Baer AA, Miller MJ, Dilger AC. Pathogens of interest to the pork industry: A review of research on interventions to assure food safety. Compr Rev Food Sci Food Saf. 2013;12(2):183-217.

14. Borch E, Arinder P. Bacteriological safety issues in red meat and readyto-eat meat products, as well as control measures. Meat Sci. 2002;62(3):381-90.

15. Centers for Disease Control and Prevention. CDC - Trichinellosis [Internet]. 2012 [cited 2017 Oct 21]. Available from: https://www.cdc.gov/parasites/trichin ellosis/

16. Centers for Disease Control and Prevention. CDC - Taeniasis [Internet]. 2013 [cited 2017 Oct 21]. Available from: https://www.cdc.gov/parasites/taenias is/

17. Davies PR. Intensive Swine Production and Pork Safety. Foodborne Pathog Dis. 2011;8(2).

18. B.C. Laws. Public Health Act [Internet]. 2017 [cited 2017 Oct 24]. Available from: http://www.bclaws.ca/civix/document /id/complete/statreg/08028_01

19. B.C. Laws. Food Safety Act [Internet]. 2017 [cited 2017 Oct 22]. Available from: http://www.bclaws.ca/EPLibraries/bcl aws_new/document/ID/freeside/00_0 2028 01\#section2

20. B.C. Laws. Food Premises Regulation [Internet]. 2017 [cited 2017 Oct 24]. Available from: http://www.bclaws.ca/Recon/docume nt/ID/freeside/11_210_99\#section14

21. Huang C. Assessment of Sous Vide Knowledge and Inspection / Cooking 
Practices. BCIT Environmental Health Journal [Internet]. 2015;

Available from:

https://circuit.bcit.ca/repository/island ora/object/repository\%3A49?solr_nav $\% 5 \mathrm{Bid} \% 5 \mathrm{D}=\mathrm{e} 25 \mathrm{c} 628390 \mathrm{bebc} 062 \mathrm{f} 82$ \&solr_nav $\% 5$ Bpage $\% 5 \mathrm{D}=0 \&$ solr_na $\mathrm{v} \% 5 \mathrm{Boffset} \% 5 \mathrm{D}=1$

22. McIntyre L. Personal communication. 2017.

23. American Meat Institute. AMI process lethality determination spreadsheet [Internet]. 2010 [cited 2017 Nov 26]. Available from: http://meatpoultryfoundation.org/cont ent/process-lethality-spreadsheet

24. Sindelar JJ, Glass K, Hanson R. Developing validated timetemperature thermal processing guidelines for ready-to-eat deli Meat and poultry products. 2013;(July).

25. NCSS Statistical Software. NCSS 12 data analysis [Internet]. 2018 [cited 2017 Nov 25]. Available from: https://www.ncss.com/software/ncss/

26. Canadian Food Inspection Agency. Annex D: Cooking Time/Temperature Tables - Canadian Food Inspection Agency [Internet]. 2013 [cited 2017 Oct 17]. Available from:

http://www.inspection.gc.ca/food/mea t-and-poultry-products/manual-ofprocedures/chapter-4/annexd/eng/1370527526866/137052757449

$3 \# \mathrm{t} 1$ 